\title{
NOTE ON PLACES AND NAMES
}

During the premodern period covered by this book, political boundaries changed, and some states known today did not exist. The Polish state, for example, transformed from a union of two independent states of the Polish Crown and the Grand Duchy of Lithuania into the Polish-Lithuanian Commonwealth. The terms "Poland" and "Poland-Lithuania" are sometimes used in the text to denote the Polish-Lithuanian Commonwealth, especially for sources in Polish, unless specific regions are pertinent. Italy as a single state did not exist; it comprised separate principalities, including the Papal States, Venetian Republic, Duchy of Milan, and others. But sources do use the term Italia, and in some cases the term Italy is used in the book. But political units that are particularly pertinent are referred to by their proper names.

Towns and cities are identified throughout according to the terminology of the period, unless an English equivalent exists. For example, present-day Vilnius in Lithuania appears as Wilno, and current-day Lviv in Ukraine is referred to as Lwów. But for Kraków, Trento, or Warszawa, for which English names exist, Cracow, Trent, and Warsaw are used. In the bibliography, the place names correspond to those in the publication itself, except for well-known places such as Rome, Venice, or Amsterdam.

Names appear the way they are shown in court records, often in Latinized form. For example, the Polish name Katarzyna is referred to as Caterina in court documents. The Latinized form, which is also easier for the English 
reader, is the version used in the book. Trent and other multilingual borderlands present a particular problem. When records exist in different languages-for example, in Latin, Italian, and German sources in Trent, where different versions of names appear-the name that corresponds to the language the person spoke is used. So, for example, the German-speaking Jew Engel, referred in Latin or Italian records as Angelus or Angelo, respectively, but in German contemporary sources as Engel, is named Engel in the book. The Trent trial was a German affair, in the German-speaking part of the town.

All translations within the text-from French, German, Hebrew, Italian, Latin, Polish, Russian, Spanish, and Yiddish-are mine, unless otherwise noted. If there exists a published English translation, usually that translation is used, unless otherwise noted. Early modern sources in English retain their spelling. 


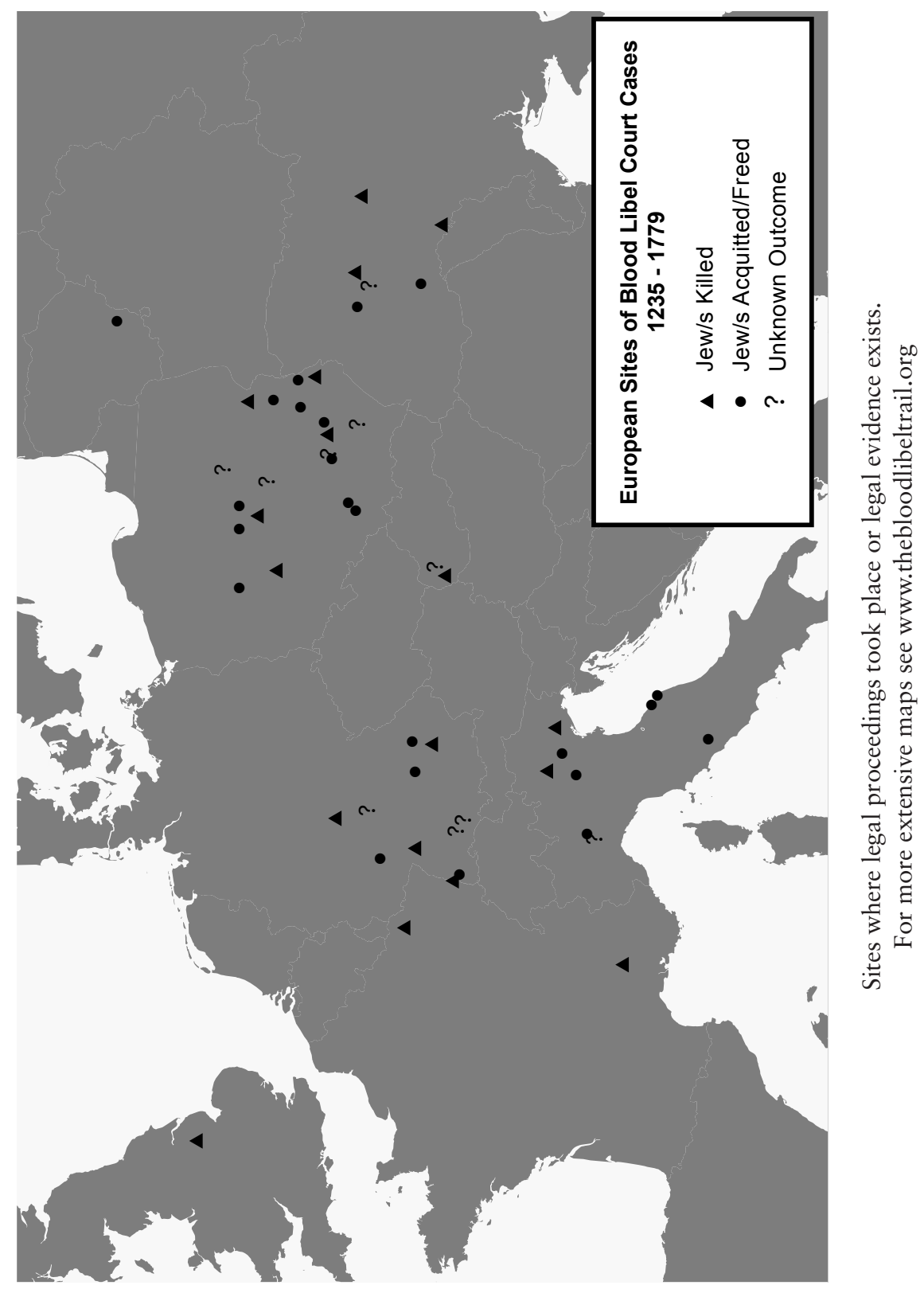



Blood Libel 
